http://dx.doi.org/10.1590/1678-4162-9201

Arq. Bras. Med. Vet. Zootec., v.69, n.1, p.225-233, 2017

\title{
Massa de forragem, composição morfológica e valor nutritivo de capim-braquiária submetido a níveis de sombreamento e fertilização
}

\author{
[Herbage mass, morphological composition and nutritive value of signalgrass, submitted \\ to shading and fertilization levels] \\ C.M. Lopes ${ }^{1}$, D.S.C. Paciullo ${ }^{2}$, S.A.C. Araújo', C.A.M. Gomide ${ }^{2}$, \\ M.J.F. Morenz ${ }^{2}$, S.D.J. Villela ${ }^{1}$ \\ ${ }^{1}$ Universidade Federal dos Vales do Jequitinhonha e Mucuri -Alto da Jacuba, Diamantina, MG \\ ${ }^{2}$ Embrapa Gado de Leite - Juiz de Fora, MG
}

\begin{abstract}
RESUMO
Características produtivas e nutricionais de Brachiaria decumbens, submetida a condições de sombreamento (sol pleno, $20 \%$ e $70 \%$ de sombreamento), sem e com uso de fertilização ( $80 \mathrm{~kg} \mathrm{ha}^{-1}$ de N e $\mathrm{K}_{2} \mathrm{O}$ e $60 \mathrm{~kg} \cdot \mathrm{ha}^{-1}$ de $\mathrm{P}_{2} \mathrm{O}_{5}$ ), foram avaliadas no delineamento de blocos casualizados, com quatro repetições. As parcelas sombreadas foram alocadas em um sistema silvipastoril, enquanto aquelas a pleno sol foram avaliadas em um monocultivo de $B$. decumbens. O sombreamento severo promoveu reduções de $54 \%$ na massa seca verde, $59 \%$ na massa seca total e $58 \%$ na densidade volumétrica de forragem. Aumentos da massa de forragem e da densidade volumétrica em resposta ao fertilizante foram observados somente nas condições de sol pleno e sombreamento moderado. A adubação não influenciou nas características nutricionais da forragem, mas o sombreamento severo promoveu aumentos de 20 e $51 \%$ nos teores de clorofila e de proteína bruta, respectivamente. Reduções dos teores de fibra em detergente neutro e fibra em detergente ácido foram observadas com o sombreamento. Os teores de lignina e a digestibilidade in vitro da matéria seca não variaram com nenhum fator estudado (médias de 6,0 e 60,9\%, respectivamente). A adubação de $B$. decumbens com dose moderada de NPK é recomendada para dosséis cultivados no sol pleno e sombreamento moderado, mas deve ser evitada em pastos severamente sombreados, pois não reflete aumento de massa de forragem nem melhorias de seu valor nutricional.
\end{abstract}

Palavras-chave: adubação de pastagens, Brachiaria decumbens, digestibilidade, proteína bruta, sistema silvipastoril

\begin{abstract}
Productive and nutritional traits of Brachiaria decumbens, submitted to shading conditions (full sun, 20\% and $70 \%$ shading) and fertilization levels (without or with $80 \mathrm{~kg} \cdot \mathrm{ha}^{-1}$ of $\mathrm{N}$ and $\mathrm{K}_{2} \mathrm{O}$ and $60 \mathrm{~kg} \cdot \mathrm{hg}^{-1}$ of $\mathrm{P}_{2} \mathrm{O}_{5}$ ), were evaluated in a randomized complete block design, with four replications. The shading were allocated in a silvopastoral system, while full sun was obtained in an exclusive B. decumbens pasture. The severe shading reduced the green dry mass in 54\%, total dry mass in 59\% and the forage bulk density in 58\%. Increases in the forage mass and forage bulk density in response to fertilization were observed only in full sun and moderate shade. The nutritional traits did not vary with fertilization, but the chlorophyll and crude protein contents increased 20 and 51\% with severe shading, respectively. The neutral detergent fiber and acid detergent fiber reduced with shade. The lignin content and in vitro dry matter digestibility did not vary with factors (average values of 6.0 and $60.9 \%$, respectively). Fertilization with moderate dose of NPK is recommended to B. decumbens in full sun and moderate shading, but should be avoided in severely shaded pasture, because not reflected in improvement of forage mass and its nutritional traits.
\end{abstract}

Keywords: Brachiaria decumbens, crude protein, digestibility, pasture fertilization, silvopastoral system

Recebido em 1 de junho de 2016

Aceito em 6 de julho de 2016

E-mail: domingos.paciullo@embrapa.br 


\section{INTRODUÇÃO}

O sistema silvipastoril, técnica de exploração agropecuária na qual se integram árvores, forrageiras e animais na mesma área, tem sido sugerido para o alcance da sustentabilidade em sistemas de produção animal. Resultados de diversos trabalhos têm indicado suas potencialidades para aumentar a fertilidade do solo, melhorar a qualidade da forragem, promover conforto térmico aos animais e propiciar diversificação de renda para o produtor (Carvalho et al., 1994; Paciullo et al., 2014). Entretanto, nos sistemas silvipastoris, o sombreamento promovido pelas árvores modifica significativamente o microclima do sub-bosque, influenciando a quantidade e a qualidade da forragem produzida (Guenni et al., 2008; Sousa, 2009; Abraham et al., 2014).

O crescimento das forrageiras em associação com espécies arbóreas pode ser prejudicado ou favorecido, dependendo de fatores como a tolerância das espécies à sombra, o grau de sombreamento proporcionado pelas árvores e a competição entre as plantas, com relação à água e nutrientes do solo (Dias-Filho, 2000; Gómez et al., 2013). Em geral as forrageiras tolerantes ao sombreamento apresentam alterações morfofisiológicas, quando cultivadas à sombra, que lhes conferem maior capacidade de produção, quando comparadas às espécies não tolerantes em cultivo sob luminosidade reduzida (Paciullo et al., 2008; Guenni et al., 2008; Veras et al., 2010; Abraham et al., 2014).

O valor nutritivo das forrageiras, definido em função de sua composição química e digestibilidade, depende de fatores químicos, físicos e estruturais inerentes à planta, que, por sua vez, são influenciados pelo meio ambiente, principalmente pelas condições edafoclimáticas. $\mathrm{O}$ ambiente luminoso, sob o qual as plantas se desenvolvem, influencia seu valor nutritivo (Abraham et al., 2014). Isso faz com que as plantas que se desenvolvem em ambientes sombreados, como em sub-bosques de sistemas silvipastoris, apresentem variações na qualidade da forragem produzida, em comparação às plantas que se desenvolvem a pleno sol (Sousa 2009; Mishara et al., 2010; Paciullo et al., 2014).

Em regiões montanhosas do Brasil, os solos apresentam normalmente elevada acidez e baixos teores de nutrientes, o que têm acarretado insuficientes massas de forragem no pasto, que se apresenta com baixo valor nutricional. O aumento de nutrientes no solo poderia beneficiar a produção e o valor nutritivo do pasto. Entretanto, a restrição de radiação em sistemas silvipastoris pode afetar a eficiência de resposta de plantas forrageiras ao fertilizante aplicado, o que depende da espécie forrageira, das condições climáticas e do nível de sombreamento imposto ao sobosque (Pandey et al., 2011; Gómez et al., 2013).

Este estudo teve como objetivo avaliar a massa e a composição morfológica da forragem e o valor nutritivo de capim-braquiária (Brachiaria decumbens Stapf.) submetido a três regimes de radiação fotossinteticamente ativa (RFA), com ou sem uso da fertilização.

\section{MATERIAL E MÉTODOS}

O experimento foi conduzido no Campo Experimental José Henrique Bruschi da Embrapa Gado de Leite, localizado no município de Coronel Pacheco - MG. As coordenadas do local são $21^{\circ} 33^{\prime} 22^{\prime}$ ' $\mathrm{S}$ e $43^{\circ} 06^{\prime} 15^{\prime}$ ' $\mathrm{W}$ e a altitude é de $410 \mathrm{~m}$. O clima da região, de acordo com a classificação de Köppen, é do tipo Cwa (mesotérmico). A média histórica de precipitação pluviométrica mensal e temperatura diária média do ar, de outubro a março, são de $230 \mathrm{~mm}$ e 24,0 ${ }^{\circ} \mathrm{C}$, respectivamente. Os dados climáticos coletados em estação meteorológica situada a $500 \mathrm{~m}$ da área experimental mostraram valores de precipitação mensal e temperatura média do ar próximos das médias históricas (precipitação mensal de $193 \mathrm{~mm}$ e temperatura média diária de $24,1{ }^{\circ} \mathrm{C}$, de outubro a março). O solo da área é classificado como Latossolo Vermelho-Amarelo distrófico, de textura argilosa.

As avalições foram realizadas em pastagens de capim-braquiária (Brachiaria decumbens Stapf. cv. Basilisk), estabelecidas em 1997, em condições de monocultivo e associada com árvores, em sistema silvipastoril. O sistema silvipastoril consiste do capim-braquiária e das espécies arbóreas Eucalyptus grandis e Acacia mangium, as quais apresentavam 25 e $20 \mathrm{~cm}$ de diâmetro à altura do peito e 14 e $22 \mathrm{~m}$ de altura, respectivamente. As árvores foram estabelecidas em nível na forma de renques arranjados com quatro linhas com espaçamento de $3 \times 3 \mathrm{~m}$ entre 
árvores na linha e entre linhas nos renques. Os renques foram espaçados de $30 \mathrm{~m}$.

No estabelecimento da forrageira e plantio das árvores, em novembro de 1997, foram realizadas adubação e calagem por meio da aplicação de $1.000 \mathrm{~kg} \cdot \mathrm{ha}^{-1}$ de calcário dolomítico, $600 \mathrm{~kg} \cdot \mathrm{ha}^{-1}$ de fosfato de Araxá, $25 \mathrm{~kg} \cdot \mathrm{ha}^{-1}$ de superfosfato simples, $100 \mathrm{~kg} \cdot \mathrm{ha}^{-1}$ de cloreto de potássio e 30kg.ha ${ }^{-1}$ de FTE BR-16. Nenhuma aplicação de corretivos ou fertilizantes foi realizada após o estabelecimento da pastagem, em novembro de 1997. O pasto de capim-braquiária foi estabelecido pelo método convencional de preparo do solo, tanto em consórcio com as árvores, como em monocultivo.

Em maio de 2010, antes do início do período experimental, foi realizada análise de solo, que apresentou os seguintes resultados: $\mathrm{pH}$ em água $=4,26$; P disponível (Mehlich-1) = 2,98 mg. $\mathrm{dm}^{-3}$; $\mathrm{Al}^{3+}=0,94 \mathrm{cmol}_{\mathrm{c}} \mathrm{dm}^{-3} ; \mathrm{K}^{+}=38,2 \mathrm{mg} \cdot \mathrm{dm}^{-3} ; \mathrm{Ca}^{2+}$

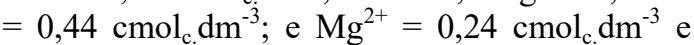
$\mathrm{V} \%=11,4 \%$

Os tratamentos foram dispostos em delineamento de blocos casualizados, em arranjo fatorial $3 \times 2$, com quatro repetições. Os tratamentos consistiram de três ambientes em termos de redução da RFA recebida pelo pasto (sol pleno ou sem redução da RFA, sombreamento moderado ou com $20 \%$ de redução da RFA e sombreamento severo ou com $70 \%$ de redução da RFA) e dois níveis de fertilização com nitrogênio, fósforo e potássio (presença ou ausência). A condição de sol pleno foi obtida na pastagem de capim-braquiária sem influência de árvores, enquanto as condições de sombra foram obtidas dentro do sistema silvipastoril, entre 8 e $12 \mathrm{~m}$ de distância do renque arborizado $(20 \%$ de sombra) e sob a copa das árvores, dentro do renque $(70 \%$ de sombra). As unidades experimentais apresentavam área igual a $20 \mathrm{~m}^{-2}$, perfazendo uma área total de $480 \mathrm{~m}^{-2}$.

Para as avaliações da RFA incidente foi utilizado o aparelho analisador de dossel - AccuPAR Linear PAR/LAI ceptometer, Modelo PAR - 80 (DECAGON Devices), com o qual foram feitas cinco leituras em cada parcela, nos horários de 9:00, 12:00 e 15:00 horas, uma vez a cada ciclo de crescimento, em dias de céu aberto.
As parcelas receberam, conforme análise de solo, dose de calcário necessária para elevação da saturação por bases do solo para $40 \%$. Os tratamentos experimentais de $\mathrm{N}-\mathrm{P}_{2} \mathrm{O}_{5}-\mathrm{K}_{2} \mathrm{O}$ foram representados pela presença ou ausência de aplicação dos fertilizantes. A adubação foi realizada em duas etapas. A primeira em novembro de 2010, após o corte de uniformização, com 40, 60 e $40 \mathrm{~kg}^{\circ} \mathrm{ha}^{-1}$ de N, $\mathrm{P}_{2} \mathrm{O}_{5}$ e $\mathrm{K}_{2} \mathrm{O}$, nas formas de ureia, superfostato simples e cloreto de potássio, respectivamente. $\mathrm{Na}$ segunda aplicação, realizada após o segundo ciclo de crescimento das plantas, foram utilizadas apenas as fontes de nitrogênio e potássio, aplicando-se as mesmas doses de $\mathrm{N}$ e $\mathrm{K}_{2} \mathrm{O}$, de forma a totalizar nas duas etapas de adubação, doses de $80 \mathrm{~kg} \cdot \mathrm{ha}^{-1}$ de N, $60 \mathrm{~kg} \cdot \mathrm{ha}^{-1}$ de $\mathrm{P}_{2} \mathrm{O}_{5}$ e $80 \mathrm{~kg} \cdot \mathrm{ha}^{-1}$ de $\mathrm{K}_{2} \mathrm{O}$.

Para este estudo, a área experimental foi submetida, a partir de fevereiro de 2010, a um manejo que preconizou o uso de metas de alturas para interrupção da rebrota $(40 \mathrm{~cm})$ e para o resíduo do pasto $(15 \mathrm{~cm})$, a fim de se obter estabilização da estrutura do dossel compatível com o manejo preconizado. As avaliações foram realizadas durante a época chuvosa na região (novembro 2010 a maio de 2011), quando ocorrem $90 \%$ da precipitação pluviométrica. O período experimental totalizou um período de 178 dias, durante os quais foram avaliados cinco ciclos de crescimento.

Duas amostras da forragem foram coletadas em cada parcela, ao final de cada ciclo de crescimento, sempre que o dossel atingia a altura média de $40 \mathrm{~cm}$. A altura foi monitorada semanalmente com o auxílio de uma régua graduada. Os cortes foram feitos no nível do solo, com auxílio de cutelo em área de $0,25 \mathrm{~m}^{2}$ $(0,5 \times 0,5 \mathrm{~m})$. As amostras foram pesadas, subamostradas e separadas nos componentes morfológicos lâmina foliar, colmo mais bainha foliar e material morto. Cada componente foi pesado e levado à estufa de ventilação forçada de ar a $55{ }^{\circ} \mathrm{C}$ por 72 horas, para determinação do teor de matéria seca. A partir dessas informações foram estimadas as massas de folha, colmo e material morto, além da massa total. A massa seca verde foi constituída pelo somatório das massas de folha e de colmo e a massa seca total representou o somatório da massa seca verde e da massa de material morto. Já a densidade de 
forragem foi calculada a partir da massa seca total dividida pela altura média do pasto.

Para a análise de composição bromatológica, foram coletadas duas amostras por parcela acima da altura de resíduo de $15 \mathrm{~cm}$, com o auxílio de uma moldura metálica de $0,5 \times 0,5 \mathrm{~m}$. Esse critério foi definido com o objetivo de se determinar o valor nutritivo da massa de forragem do extrato pastejável, localizado acima da altura residual. As amostras foram secas em estufa de ventilação forçada de ar, à temperatura de $55{ }^{\circ} \mathrm{C}$, até peso constante. As amostras foram moídas a $1 \mathrm{~mm}$ e analisadas quanto aos teores de nitrogênio (AOAC, 2009), sendo a proteína bruta (PB) calculada pelo teor de nitrogênio multiplicado por 6,25; fibra em detergente neutro (FDN), fibra em detergente ácido (FDA) e lignina, conforme Van Soest et al. (1991) e digestibilidade in vitro da matéria seca (DIVMS), segundo Tilley e Terry (1963).

Antes de cada coleta, foram realizadas medidas indiretas dos teores de clorofila, na última folha completamente expandida de cinco perfilhos de cada parcela, utilizando medidor Minolta SPAD $-502 \mathrm{~S}$.

Os dados foram analisados com os valores médios dos ciclos de crescimento das plantas. Realizou-se a verificação dos pressupostos para ANOVA no conjunto de dados que foi analisado por meio do procedimento MIXED do pacote estatístico Statistical Analysis System (SAS), versão 9.0 para Windows. A escolha da matriz de variância e de covariância foi feita utilizando-se o Critério de Informação de Akaike (Wolfinger, 1993) e a análise de variância feita com base nas seguintes causas de variação: RFA incidente, fertilização e a interação entre elas. Os efeitos de RFA incidente e fertilização e a interação entre os fatores foram considerados fixos. Como efeito aleatório foi considerado o erro experimental entre unidades. As médias dos tratamentos foram comparadas com emprego do teste LSMENS $(\mathrm{P}<0,05)$.

\section{RESULTADOS E DISCUSSÃO}

As massas secas de folha, colmo e verde foram influenciadas pela interação entre o nível de sombreamento e a fertilização $(\mathrm{P}=0,0027$; $\mathrm{P}=0,0032$ e $\mathrm{P}=0,0024$ para massa de folha, colmo e verde, respectivamente) (Tab. 1).
As menores massas para os três componentes foram observadas na sombra severa, independentemente da fertilização. Para a massa de folha não houve diferença entre o sol pleno e a sombra moderada, mas para o colmo e a massa seca verde o sombreamento, independentemente da intensidade, promoveu diminuição dos valores. A semelhança da massa de folhas, nas condições de sol pleno e $20 \%$ de sombra, pode ser explicada pelo substancial investimento de carbono para expansão da área foliar em plantas submetidas à sombra, estratégia que visa o aumento na captura de luz. Este fenômeno é resultado de uma mudança no padrão de alocação de biomassa na planta, caracterizado pela prioridade de crescimento da parte aérea, especialmente folhas, em detrimento do sistema radicular (Guenni et al., 2008). O aumento de área foliar é acompanhado pela diminuição da espessura da lâmina foliar, do que resultam maiores valores de área foliar específica em ambientes sombreados. Do ponto de vista fisiológico essas mudanças contribuem para a redução do gasto energético para síntese de novos tecidos foliares e para manutenção da integridade fotossintética das folhas moderadamente sombreadas. Nestas condições, a eficiência de uso da RFA é mantida ou mesmo aumentada quando comparada a plantas que se desenvolvem sob luz plena (Gómez et al., 2013).

Embora a massa de folhas não tenha sofrido modificação com o sombreamento moderado, houve redução da massa seca verde, quando se comparam as condições de sol pleno e sombreamento moderado (Tab. 1). Algumas gramíneas tropicais têm revelado capacidade para continuar produzindo satisfatoriamente, ou até mesmo aumentar a produção de massa, em condições de sombra moderada (Gómez et al., 2013; Santiago-Hernandéz et al., 2015). Segundo Abraham et al. (2014), o crescimento de forrageiras pode ser beneficiado pelo sombreamento em condições de restrição hídrica, devido à redução na evapotranspiração e aumento da umidade do solo, o que explicaria a assertiva acima. Neste estudo, considera-se que não houve restrição de água no solo, tendo em vista a adequada quantidade de chuvas (193 mm.mês ${ }^{-1}$, totalizando $1158 \mathrm{~mm}$ no período experimental) observada durante o período experimental. Neste caso, a RFA se tornou um fator mais limitante para o crescimento do pasto do que a umidade do solo. Este fato explica os 
decréscimos da massa seca verde nas condições de sombreamento. Embora no sombreamento moderado a redução da massa de forragem tenha sido de pequena magnitude, a queda acentuada no sombreamento severo revela o baixo potencial para produção de forragem em condições de sombreamento intenso. A forte restrição de RFA compromete a capacidade fotossintética das plantas (Santiago-Hernandéz et al., 2015) e afeta significativamente a produção de massa de gramíneas forrageiras. Como consequência, o sombreamento excessivo pode limitar de maneira acentuada o potencial para produção animal e a persistência da pastagem em sistemas silvipastoris, motivos pelos quais deve ser evitado.

Tabela 1. Massa seca dos componentes morfológicos $\left(\mathrm{kg} \cdot \mathrm{ha}^{-1}\right)$ e densidade volumétrica da forragem (MS $\left.\mathrm{kg} \cdot \mathrm{ha}^{-1} \cdot \mathrm{cm}^{-1}\right)$ do capim-braquiária em função do nível de sombreamento e do uso da fertilização

\begin{tabular}{|c|c|c|c|c|c|}
\hline \multirow{2}{*}{ Fertilização } & \multicolumn{3}{|c|}{ Sombreamento (\%) } & \multirow{2}{*}{$P$-value } & \multirow{2}{*}{$\mathrm{EPM}^{*}$} \\
\hline & 0 & 20 & 70 & & \\
\hline \multicolumn{6}{|c|}{ Massa de Folha } \\
\hline Ausente & $864 \mathrm{Ab}$ & $807 \mathrm{Ab}$ & $471 \mathrm{Bb}$ & \multirow{2}{*}{0,0027} & \multirow{2}{*}{33,5} \\
\hline Presente & $1070 \mathrm{Aa}$ & $1012 \mathrm{Aa}$ & $439 \mathrm{Ba}$ & & \\
\hline \multicolumn{6}{|c|}{ Massa de Colmo } \\
\hline Ausente & $992 \mathrm{Ab}$ & $820 \mathrm{Bb}$ & $529 \mathrm{Ca}$ & \multirow{2}{*}{0,0032} & \multirow{2}{*}{40,2} \\
\hline Presente & 1299Aa & $1002 \mathrm{Ba}$ & $516 \mathrm{Ca}$ & & \\
\hline \multicolumn{4}{|c|}{ Massa Seca Verde } & \multirow{4}{*}{0,0024} & \multirow{3}{*}{70,5} \\
\hline Ausente & $1857 \mathrm{Ab}$ & $1627 \mathrm{Bb}$ & $1001 \mathrm{Ca}$ & & \\
\hline \multirow[t]{2}{*}{ Presente } & $2370 \mathrm{Aa}$ & $2015 \mathrm{Ba}$ & $956 \mathrm{Ca}$ & & \\
\hline & & dade volu & & & \\
\hline Ausente & $46,0 \mathrm{Ab}$ & $38,7 \mathrm{Bb}$ & $22,8 \mathrm{Ca}$ & \multirow{2}{*}{0,0198} & \multirow{2}{*}{2,21} \\
\hline Presente & $57,6 \mathrm{Aa}$ & $46,5 \mathrm{Ba}$ & $20,9 \mathrm{Ca}$ & & \\
\hline
\end{tabular}

Médias seguidas por letras diferentes, maiúsculas nas linhas e minúsculas nas colunas, dentro de cada característica, diferem entre si $(\mathrm{P}<0,05)$.

* EPM = erro padrão da média.

A fertilização foi efetiva para promover aumentos de massa de folha, colmo e verde com sol pleno e sombra moderada, mas não houve resposta à fertilização em plantas submetidas ao sombreamento severo (Tab. 1). Pandey et al. (2011) relataram respostas positivas de três gramíneas ao fertilizante aplicado até a dose de $120 \mathrm{~kg} \cdot \mathrm{ha}^{-1} \cdot$ ano $^{-1}$. Entretanto, foi constato que a eficiência de resposta ao nutriente aplicado foi inversamente proporcional à percentagem de sombreamento imposta ao pasto. A resposta positiva ao fertilizante em condições de sombra moderada corrobora estudos que demostraram benefícios da fertilização em ambientes com luminosidade moderadamente reduzida e com uso de doses moderadas de adubo (Pandey et al., 2011; Gomez et al., 2013). Na maioria dos casos, sombreamento acima de $50 \%$ da RFA reduz acentuadamente a produção de massa de forragem (Abraham et al., 2014) e a resposta do pasto ao adubo aplicado (Guenni et al., 2008; Pandey et al., 2011), tornando a prática da adubação questionável nesses casos.
Interação significativa entre o nível de sombreamento e a fertilização foi observada $(\mathrm{P}=0,0198)$ para a densidade volumétrica de forragem (Tab. 1). A sombra reduziu significativamente a densidade volumétrica para ambas as condições de fertilização. Quando comparadas às condições de sol pleno, a densidade volumétrica foi reduzida em 16 e 19\%, na sombra moderada, e em 50 e $64 \%$, no sombreamento severo, respectivamente para os tratamentos sem e com fertilização. Verificou-se aumento da densidade volumétrica em resposta à adubação no sol pleno e no sombreamento moderado, mas em condições de sombra intensa não houve efeito da fertilização.

A redução da densidade volumétrica de forragem com o aumento do sombreamento ocorreu pelo fato de a massa de forragem também ter diminuído nas condições de sombra, tendo em vista que a altura das plantas no momento da colheita da forragem foi a mesma para todos os tratamentos. Os valores observados são 
considerados baixos, mesmo aqueles obtidos a sol pleno e com aplicação de fertilizante. Santos et al. (2010) trabalhando com B. decumbens mantida em quatro alturas $(10,20,30$ e $40 \mathrm{~cm})$ sob lotação contínua, verificaram densidades volumétricas de forragem maiores do que as encontradas neste estudo. Para o pasto mantido a de $40 \mathrm{~cm}$ de altura, os autores encontraram densidade de $107 \quad \mathrm{~kg} \cdot \mathrm{ha}^{-1} \cdot \mathrm{cm}^{-1}$, valor praticamente duas vezes maior que o verificado no pasto que recebeu adubação a pleno sol $(57,6$ $\left.\mathrm{kg} \cdot \mathrm{ha}^{-1} \cdot \mathrm{cm}^{-1}\right)$. Essa diferença pode ser devida à maior dose de nitrogênio aplicada no referido trabalho $\left(150 \mathrm{~kg} \cdot \mathrm{ha}^{-1} \cdot \mathrm{ano}^{-1}\right)$, quando comparada à fertilização usada no presente estudo $\left(80 \mathrm{~kg} \cdot \mathrm{ha}^{-}\right.$ ${ }^{1}$.ano $\left.{ }^{-1}\right)$. Como verificado neste trabalho, a fertilização influencia positivamente na densidade de forragem, o que respalda a hipótese formulada acima. As baixas densidades de forragem na sombra intensa poderiam diminuir acentuadamente o tamanho do bocado e a ingestão de forragem por animais em pastejo (Sarmento, 2003), o que reforça a assertiva de que sombreamentos severos podem comprometer a produção animal em sistemas silvipastoris.

A massa seca de material morto e a massa seca total foram influenciadas $(\mathrm{P}<0,001$ e $\mathrm{P}=0,002$ para material morto e massa total, respectivamente) apenas pelo nível de sombreamento, não apresentando efeito $(\mathrm{P}>0,05)$ de fertilização ou da interação entre os fatores (Tab. 2). Ambas as variáveis apresentaram redução nos valores com o aumento do sombreamento, seguindo o padrão observado para as massas secas de colmo e verde.

Tabela 2. Massa seca de material morto (MSMM) e total (MSTO) (kg.ha ${ }^{-1}$ ) e percentagens de folha (FO), colmo $(\mathrm{CO})$ e material morto $(\mathrm{MM})$ na massa total do capim-braquiária, em função do nível de sombreamento e do uso da fertilização

\begin{tabular}{|c|c|c|c|c|c|c|c|c|c|}
\hline \multirow{2}{*}{ Item } & \multicolumn{3}{|c|}{ Sombreamento $(\%)$} & \multirow{2}{*}{ P-value } & \multirow{2}{*}{ EPM } & \multicolumn{2}{|c|}{ Fertilização } & \multirow[b]{2}{*}{ P-value } & \multirow{2}{*}{$\mathrm{EPM}^{*}$} \\
\hline & 0 & 20 & 70 & & & Ausente & Presente & & \\
\hline MSMM & $1033 \mathrm{~A}$ & $825 \mathrm{~B}$ & $296 C$ & $<0,001$ & 28,9 & 752 & 684 & 0,365 & 32,6 \\
\hline MSTO & $3148 \mathrm{~A}$ & $2646 \mathrm{~B}$ & $1275 \mathrm{C}$ & 0,002 & 100,2 & 2248 & 2464 & 0,253 & 96,2 \\
\hline FO & $30,3 \mathrm{~B}$ & $34,2 \mathrm{~A}$ & $36,7 \mathrm{~A}$ & $<0,001$ & 0,52 & $32,7 \mathrm{~B}$ & $34,7 \mathrm{~A}$ & 0,003 & 0,43 \\
\hline $\mathrm{CO}$ & $35,9 \mathrm{~B}$ & $34,3 \mathrm{~B}$ & $40,7 \mathrm{~A}$ & 0,004 & 0,82 & $35,6 \mathrm{~B}$ & $38,4 \mathrm{~A}$ & 0,010 & 0,67 \\
\hline MM & $33,7 \mathrm{~A}$ & $31,4 \mathrm{~A}$ & $22,6 \mathrm{~B}$ & $<0,001$ & 1,06 & $31,6 \mathrm{~A}$ & $26,9 \mathrm{~B}$ & 0,001 & 0,86 \\
\hline
\end{tabular}

Médias seguidas por letras diferentes, comparando níveis de sombreamento ou fertilização, diferem entre si $(\mathrm{P}<0,05)$. *EPM = erro padrão da média.

As percentagens de folha, colmo e material morto variaram de acordo com o nível de sombreamento $(\mathrm{P}<0,001 ; \mathrm{P}=0,04$ e $\mathrm{P}<0,001$ para folha, colmo e material morto, respectivamente) e a fertilização $(\mathrm{P}=0,003 ; \mathrm{P}=0,010$ e $\mathrm{P}=0,001$ para folha, colmo e material morto, respectivamente) (Tab. 2). Maior $\%$ de folha foi observada nas duas condições de sombreamento e maior \% colmo foi verificada na sombra severa. Comportamento inverso foi observado para a \% de material morto, a qual foi maior no sol pleno e na sombra moderada e menor na sombra severa.

A maior proporção de folhas em dosséis mantidos à sombra poderia evidenciar a priorização das plantas na alocação de fotoassimilados para formação de folhas, com vistas ao aumento na captação de RFA. De fato, em condições de sombreamento ocorre aumento das taxas de alongamento de folhas, resultando em folhas mais longas e de maior área (Paciullo et al., 2008; Abraham et al., 2014). Por outro lado, concomitantemente ao aumento da taxa de alongamento, se observa aumento da área foliar específica, como resultado da expansão da área foliar relativamente a seu peso. Nos resultados ora relatados, merece destaque a forte redução da $\%$ de material morto com o sombreamento severo (33\% quando comparada ao sol pleno), o que pode estar relacionado às maiores percentagens de folhas na sombra severa. Sousa (2009) discute sobre um mecanismo relacionado ao atraso no desenvolvimento ontogenético de plantas cultivadas à sombra mais intensa. Neste caso, as forrageiras tendem a ser mais jovens fisiologicamente, o que prolonga a fase vegetativa, reduzindo a senescência e o acúmulo de material morto.

Os teores de clorofila SPAD foram influenciados pelo sombreamento $(\mathrm{P}=0,0365)$ e pela fertilização ( $\mathrm{P}=0,0441)$, não apresentando efeito $(\mathrm{P}>0,05)$ da interação entre os fatores. A 
clorofila SPAD foi maior nas condições de sombreamento severo, não mostrando diferença entre o sol pleno e o sombreamento moderado (Tab. 3). Maiores concentrações de clorofila em plantas sombreadas são consistentes com resultados apresentado por Singh (1994) e Mishara et al. (2010). Em revisão sobre o assunto, Sousa (2009) relata que a menor degradação de moléculas de clorofila por fotooxidação, em plantas com radiação restrita, permite manutenção de maiores teores de clorofila em folhas desenvolvidas à sombra. Além disso, o aumento do teor de clorofila pode estar ligado ao maior desenvolvimento de grana, conjunto de discos membranáceos (tilacóides), dispostos em pilha, que contêm clorofila e estão localizados nos cloroplastos. Quando ao efeito da fertilização, observou-se maior teor em parcelas onde foi aplicado o fertilizante $(37,0$ e 39,1 , para adubação ausente e presente, respectivamente). Este resultado refletiu a maior disponibilização de nitrogênio no solo, pela a fertilização, o que provavelmente favoreceu a síntese de molécula de clorofila.

Os teores de PB, FDN e FDA variaram com o nível de sombreamento $(\mathrm{P}<0,0001 ; \mathrm{P}=0,0020 \mathrm{e}$ $\mathrm{P}=0,0168$ para $\mathrm{PB}, \quad \mathrm{FDN}$ e FDA, respectivamente), mas não foram influenciados $(\mathrm{P}>0,05)$ pela fertilização nem pela interação entre os fatores. Os teores de lignina e os coeficientes de DIVMS não variaram $(\mathrm{P}>0,05)$ com os fatores (Tab. 3).

O aumento do teor proteico em resposta ao sombreamento confirma resultados obtidos em outros trabalhos com gramíneas tropicais (Neel et al., 2008; Sousa, 2009; Mishara et al., 2010; Paciullo et al., 2014). Este aumento pode estar relacionado à intensificação da degradação da matéria orgânica e da reciclagem de nitrogênio no solo sob influência do sombreamento (Wilson, 1996), favorecendo a disponibilização de nitrogênio no solo e sua absorção pelas plantas (Xavier et al., 2014). Outro mecanismo que explica o aumento do teor de PB à sombra se baseia na teoria da diluição do nitrogênio e na proposição da existência de uma percentagem de nitrogênio ideal para determinado nível de produção de MS na planta (Leimare e Chartier, 1992). Dessa forma, plantas submetidas ao sombreamento reduzem seu crescimento e podem apresentar um desbalanço na assimilação de carborno e nitrogênio, em função da absorção de nitrogênio exceder seus requerimentos metabólicos (Dale e Causton, 1992). A maior massa de forragem a pleno sol (Tab. 1), provavelmente contribuiu para maior diluição e translocação do nitrogênio absorvido para as partes aéreas, em relação às plantas sombreadas, para as quais se observou menor massa de forragem e elevados teores de $\mathrm{PB}$, especialmente aquelas severamente sombreadas.

Tabela 3. Clorofila SPAD, teores (\% da MS) de proteína bruta (PB), fibra em detergente neutro (FDN), fibra em detergente ácido (FDA) e lignina e digestibilidade in vitro da MS (DIVMS - \%) do capimbraquiária em função do nível de sombreamento

\begin{tabular}{|c|c|c|c|c|c|}
\hline \multirow{2}{*}{ Variável } & \multicolumn{3}{|c|}{ Sombreamento (\%) } & \multirow{2}{*}{$P$-value } & \multirow{2}{*}{ EPM* } \\
\hline & 0 & 20 & 70 & & \\
\hline Clorofila & $34,8 \mathrm{~B}$ & $37,5 \mathrm{~B}$ & $41,6 \mathrm{~A}$ & 0,0365 & 0,56 \\
\hline PB & $9,7 \mathrm{C}$ & $11,0 \mathrm{~B}$ & $14,7 \mathrm{~A}$ & $<0,0001$ & 0,16 \\
\hline FDN & $66,6 \mathrm{~A}$ & $65,1 \mathrm{~B}$ & $64,1 \mathrm{C}$ & 0,0020 & 0,30 \\
\hline FDA & $33,0 \mathrm{~A}$ & $32,2 \mathrm{~B}$ & $31,8 \mathrm{~B}$ & 0,0168 & 0,26 \\
\hline Lignina & $5,4 \mathrm{~A}$ & $6,1 \mathrm{~A}$ & $6,7 \mathrm{~A}$ & 0,0393 & 0,26 \\
\hline DIVMS & $60,9 \mathrm{~A}$ & $61,0 \mathrm{~A}$ & $60,9 \mathrm{~A}$ & 0,3524 & 1,09 \\
\hline
\end{tabular}

Médias seguidas por letras diferentes, nas linhas, diferem entre si $(\mathrm{P}<0,05)$.

* EPM = erro padrão da média.

Para os teores de FDA e FDN observou-se redução em função do aumento do nível de sombreamento (Tab. 3), padrão também observado por Deinum et al. (1996). Segundo Kephart e Buxton, (1993), a redução nos teores de FDN e FDA em plantas sombreadas pode estar relacionada com a menor disponibilidade de fotoassimilados para o desenvolvimento da parede celular secundária, reduzindo, assim, o teor de parede e de seus constituintes.

O aumento dos teores proteicos com o sombreamento não repercutiu em melhorias da digestibilidade da forragem, tendo em vista a 
ausência de efeito da sombra na DIVMS. Este resultado confirma relatos prévios que investigaram o efeito da sombra na DIVMS (Sousa 2009; Paciullo et al., 2014). Entretanto, as informações disponíveis sobre as consequências da restrição de radiação na digestibilidade de forrageiras são contraditórias. Deinum et al. (1996) verificaram aumento da DIVMS em Setaria sphacelata e redução em Panicum maximum, enquanto Senanayake (1995), trabalhando com quatro gramíneas forrageiras, observou redução da DIVMS na sombra severa, mas aumento sob sombreamento moderado. Também Carvalho et al. (1994) relataram resultados distintos conforme a época do ano: a DIVMS de $B$. decumbens não se alterou com o sombreamento na época chuvosa, mas aumentou com a sombra durante a época seca do ano.

\section{CONCLUSÕES}

$O$ uso de dose moderada de fertilizante em pastagem de $B$. decumbens em sol pleno ou sombreamento moderado proporciona aumento da massa seca verde e da densidade volumétrica do pasto, embora não modifique $o$ valor nutricional da forragem. Em condições de sombreamento severo, apesar do aumento do teor proteico na forragem, há acentuado comprometimento da massa e da densidade volumétrica do pasto, o que não pode ser compensado por meio da adubação, de forma que tal condição deve ser evitada em sistemas silvipastoris voltados primariamente à produção animal.

\section{REFERÊNCIAS}

ABRAHAM, E.M., KYRIAZOPOULOS, A.P.; PARISSI, Z.M. et al. Growth, dry matter production, phenotypic plasticity, and nutritive value of three natural populations of Dactylis glomerata L. under various shading treatments. Agrof. Syst., v.88, p. 287-299, 2014.

ASSOCIATION OF OFFICIAL ANALYTICAL CHEMISTS (1990) (Gaithersburg, Estados Unidos). Official methods of analysis.15th ed. Richmond, 1298p.
CARVALHO, M.M.; FREITAS, V.P.; ALMEIDA, D.S. et al. Efeito de árvores isoladas sobre a disponibilidade e composição mineral da forragem de pastagens de braquiária. Rev. da Soc. Bras. Zootec., v.23, p.709-718, 1994.

DALE M.P.; CAUSTON D.R. The ecophysiology of Veronica chamaedrys, $V$. montana and $V$. officinalis. IV. Effects of shading on nutrient allocations -a field experiment. J. Ecol., v.80, p.517-526, 1992.

DEINUM, B.; SULASTRI, R.D.; ZEINAB, M.H.J. et al. Effects of light intensity on growth, anatomy and forage quality of two tropical grasses (Brachiaria brizantha and Panicum maximum var. Trichoglume). Nether. J. of Agric. Sci., v.44, p. 111-124, 1996.

DIAS-FILHO, M.B. Growth and biomass allocation of the $\mathrm{C} 4$ grasses Brachiaria brizantha and B. humidicola under shade. Pesq. Agropec. Bras., v.35, n.12, p.2335-2341, 2000.

GÓMEZ S.; GUENNI, O.; BRAVO DE GUENNI, L. Growth, leaf photosynthesis and canopy light use efficiency under differing irradiance and soil $\mathrm{N}$ supplies in the forage grass Brachiaria decumbens Stapf. Grass and Forage Sci., 68, 395-407, 2013.

GUENNI, O.; SEITER, S.; FIGUEROA, R. Growth responses of three Brachiaria species to light intensity and nitrogen supply. Trop. Grassl., v.42, p.75-87, 2008.

KEPHART, K.D.; BUXTON, D.R. Forage quality response of $\mathrm{C} 3$ and $\mathrm{c} 4$ perennial grasses to shade. Crop Sci., v.33, p.831-837, 1993.

LEMAIRE, G.; CHARTIER, M. Relationships between growth dynamics and nitrogen uptake for individual sorghum plants growing at different plant densities. In: LEMAIRE, G. (Ed.) Diagnosis of the nitrogen status in crops. Paris: INRA - Station decophysiologie des Plantes Fourragères, p.3-43. 1992.

MISHRA, A.K.; TIWARI, H.S.; BHATT, R.K. Growth, biomass production and photosynthesis of Cenchrus ciliaris L. under Acacia tortilis (Forssk.) Hayne based silvopastoral systems in semi arid tropics. J. Environ. Biol., v.31, p.987993, 2010 . 
PACIULLO, D.S.C.; CAMPOS, N.R.; GOMIDE, C.A.M. et al. Crescimento do pasto de capim-braquiária influenciado pelo nível de sombreamento e pela a estação do ano. Pesq. Agropec. Bras., v.43, p.317-323, 2008.

PACIULLO, D.S.C.; PIRES, M.F.A.; AROEIRA, L.J.M. et al. Sward characteristics and performance of dairy cows in organic grasslegume pastures shaded by tropical trees. Animal, v.8, p.1264-1271, 2014.

PANDEY, C.B., VERMA, S.K., DAGAR, R.C. et al. Forage production and nitrogen nutrition in three grasses under coconut tree shades in the humid-tropics. Agrof. Syst. v.83, p.1-12, 2011. RIBASKI, J.;

SARMENTO, D.O.L. Comportamento ingestivo de bovinos em pastos de capim-Marandu submetidos a regimes de lotação contínua. Piracicaba, 2003. 76 f. Dissertação (Mestrado em Zootecnia) - ESALQ/Universidade de São Paulo, Piracicaba, SP.

SILVA, J.S.; QUEIROZ, A.C. Análise de alimentos: métodos químicos e biológicos. 3.ed. Viçosa: UFV, p.235. 2002.

SENANAYAKE, S.G.J. The effect of different light levels on the nutritive quality of four natural tropical grasses. Trop. Grassl., v. 29, p.1111$1114,1995$.
SOUSA, L.F. Brachiaria brizantha cv. Marandu em sistema silvipastoril e monoculivo. 2009. 166p. Tese (Doutorado). Universidade Federal de Minas Gerais, Belo Horizonte.

TILLY, J.M.A.; TERRY, R.A.A. A two stage technique for the in vitro digestion of forage crops. J. Brit. Grassl. Soc., v.18, p.104-111, 1963.

VAN SOEST, P.J.; ROBERTSON, P.J.; LEWIS, J.B. A method for dietary fiber, neutral detergent fiber, and non starch polysaccharides in relation to animal nutrition. J. Dairy Sci., v.74, p.35833597, 1991.

VERAS, V.S.; OLIVEIRA, M.S.B.; LACERDA, T.B. et al. Produção de biomassa e estrutura do pasto de capim-andropogon em sistema silvipastoril e monoculture. Arq. Bras. Med. Vet. Zootec., v.62, p.200-207, 2010.

WILSON, J.R. Shade-stimulated growth and nitrogen uptake by pasture grasses in a subtropical environment. Aust. J. Agric. Res., v.47, p.1075-1093, 1996.

WOLFINGER, R. Covariance structure selection in general mixed models. Communication in Statistics, v.22, p.1079-1106, 1993.

XAVIER D.F., LÉDO F.J.S., PACIULLO D.S.C. et al. Nitrogen cycling in a Brachiariabased silvopastoral system in the Atlantic forest region of Minas Gerais, Brazil. Nutr. Cyc. in Agroec., v.99, 45-62, 2014. 